\section{Air pollution emission from the copper smelter Complex Bor in Serbia}

\author{
Andjela B Stanojevic* \\ Environmental Engineering, Faculty of Environmental Sciences, University in Prague, Czech Republic
}

Received: 08 April, 2021

Accepted: 22 April, 2021

Published: 26 April, 2021

*Corresponding author: Andjela B Stanojevic, Environmental Engineering, Faculty of Environmental Sciences, University in Prague, Kamýcká 129, 16500 Praha-Suchdol, Czechia, Czech Republic, Tel: +38163436436, +420776521504; Fax: +381 113572835; E-mail: xstaa030@studenti.czu.cz, andjelastanojevic157@gmail.com

ORCID: https://orcid.org/0000-0001-6258-4118

Keywords: SO2; PM particles; Environment; Health risk

https://www.peertechzpublications.com

\begin{abstract}
Ever since the industrial revolution, air got significantly polluted by the industry. Air pollution is even more concentrated in cities that have an industrial zone. Especially in these zones, the presence of Sulfur-dioxide $\left(\mathrm{SO}_{2}\right)$ and suspended Particles (PM) in the air is very high. Prolonged exposure to $\mathrm{SO}_{2}$ and $\mathrm{PM}$ can cause cancer, cardiovascular and respiratory disorders in humans. The aim of this paper was to a review available literature on air pollution by sulfur dioxide and suspended particles in the air region of Bor Copper complex, as well as to determine whether the investigated results are contradictory. Studies from prior years (2004-2015), as well as 2019, indicate rise of $\mathrm{SO}_{2}$ and $\mathrm{PM}$ air pollutants in the atmosphere in the region of the copper smelter of the Bor Complex in Serbia, which can cause serious consequences for human well-being. However, the results of research by different authors for the same years are not in agreement, with that said, a review of the literature indicates significant differences. In addition, no continuous research on any air pollutants has been done for several consecutive years. This can be an interesting question for the scientific public in Serbia. Review of available literature indicates that in Serbia, solving this problem must be taken more seriously.
\end{abstract}

\section{Introduction}

Serbian Bor Copper complex is a copper mining and smelting complex situated in the city of Bor, set in the mountainous part of eastern Serbia (Figure 1). As the amount of rich copper ore deposits is one of the largest in Europe, this area has been regarded as the center for acquiring copper for almost a century, however, the consequence is air pollution. Air pollution in this area has been assessed as one of the major environmental problems in Serbia. Emissions from Cooper Smelter are the largest source of sulfur oxides (SOx) and trace elements (in PM) such as: $\mathrm{Pb}, \mathrm{Cd}$, As, Ni [1-4]. Wind directions in this part of Europe promote air pollution in Bor region. Suspended particles have a pollution scope of $2-3 \mathrm{~km}$, while $\mathrm{SO}_{2}$ has a range of as much as $15 \mathrm{~km}[1]$.

Sulfur-dioxide is a very serious air pollutant that can change climate, degrade visibility and contribute to acid deposition, it has negative influence on the environment, and represents an important health risk $[2,5,6]$. Sulfur-dioxide is an irritant gas which in high concentrations adversely affects the respiratory system and skin, as well as the mucous membranes of the throat, eyes and nose [6]. Inhalation of higher concentrations of $\mathrm{SO}_{2}$ can lead to a buildup of water in the lungs and decrease of oxygen in the blood [7]. In addition, higher concentrations of $\mathrm{SO}_{2}$ in the air also have a detrimental effect on plants and animals [2].

Due to the application of pyro-metallurgical processes in copper smelters, significant air pollution occurs with suspended particles. These particles contain high concentrations of Lead $(\mathrm{Pb})$, Cadmium (Cd), Nickel (Ni) and Arsenic (As) $[1,8,9]$. In the case of long-term inhalation of these particles, there is a risk of cancer formation (lungs, kidneys, skin, bladder, prostate, liver) as well as for the development of heart disease, which could increase human mortality [6]. Suspended particles with a diameter of less than $2.5 \mu$ m ("fine particles" - $\mathrm{PM}_{2.5}$ ) and particles with a diameter of less than $0.1 \mu \mathrm{m}$ ("ultrafine particles" - $\mathrm{PM}_{0.1}$ ) pose a grave danger to human health. Namely, these very tiny particles can enter the airways and lungs quite deeply and the amount of deposition in the respiratory system is very high [1]. 


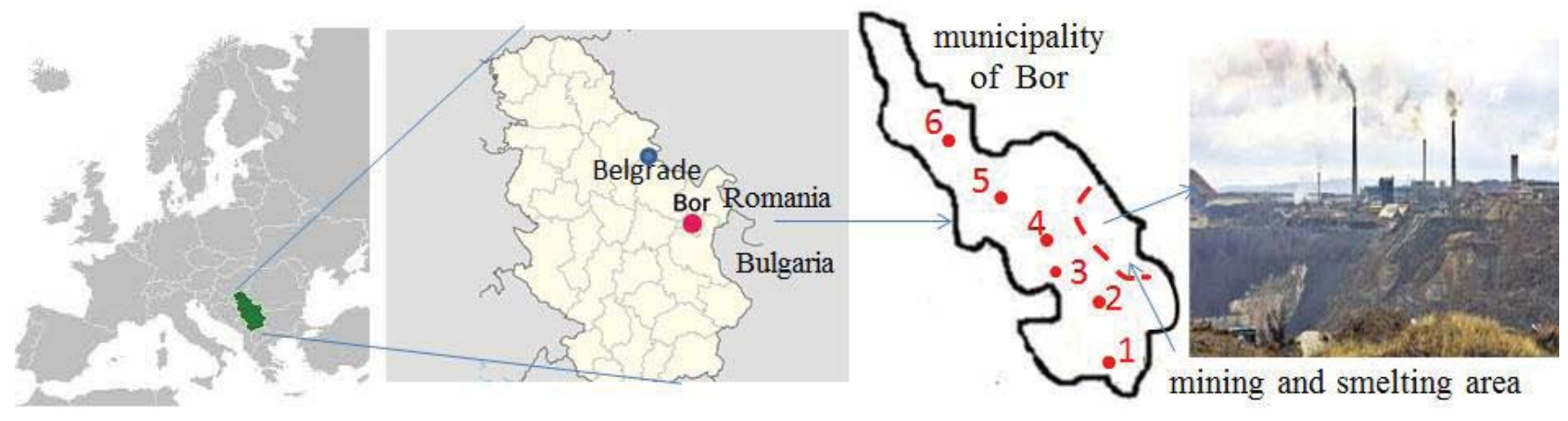

Figure 1: Map of Serbia in Europe and the position of the municipality of Bor in Serbia, as well as the location of the measuring points (1. location of the village of Slatina; 2. location of the industrial zone "Jugopetrol"; 3 . location of the Technical Faculty; 4. location of the Town Park; 5 . location of the Institute of mining and metallurgy; 6. location of the village of Brezonik).

Due to a negative effect on human health, European Union has limited the concentration of $\mathrm{SO}_{2}$ in the atmosphere to hourly limit value of $350 \mu \mathrm{g} / \mathrm{m}^{3}$ (concentration must not be greater than this 24 times per year), daily limit is $125 \mu \mathrm{g} / \mathrm{m}^{3}$ (concentration must not be greater than 3 this times per year), and mean annual value is $50 \mu \mathrm{g} / \mathrm{m}^{3}$. For protection of ecosystems annual limit concentration of $\mathrm{SO}_{2}$ in the atmosphere is $20 \mu \mathrm{g} / \mathrm{m}^{3}$ $[10,11]$. Daily limit for fine particles $\left(\mathrm{PM}_{2.5}\right)$ is $25 \mu \mathrm{g} / \mathrm{m}^{3}$ and for $\mathrm{PM}_{10}$ particles is $50 \mu \mathrm{g} / \mathrm{m}^{3}$ [11].

At the end of August 1918, the Chinese company Zijin Mining Group was chosen as a strategic partner of the mining and smelting complex Bor. Zijin Mining Group has committed to invest \$ 136 million in ecology and environmental issues. However, Cooper smelter Bor is still one of the major environmental problems in Serbia.

Taking into account the location of this smelting plant (500m from Bor city center) and dominant wind direction these pollutants have heavy impact on people of Bor and surrounding areas. The aim of this paper was to review available literature showing the results of various studies on air pollution by sulfur dioxide and suspended particles in the air of Bor Copper complex. The aim was also to determine whether the investigated results are contradictory.

\section{Methods}

\section{Study areas}

This research of literature is concentrated on different places in the municipalities of Bor, which are shown in Figure 1.

\section{Analysis of $\mathrm{SO}_{2}$ and PM concentration}

Automatic measuring stations for real-time determination of $\mathrm{SO}_{2}$ content were located on all measuring points. The content of $\mathrm{SO}_{2}$ presented in the paper was usually measured by UV-fluorescence method, using reference method EN14212:2005 [12]. The reference method presented in the paper for sampling and measurement of $\mathrm{PM}_{10}$ is defined by the protocol EN2341:1999 [13]. The Environmental protection agency of the Republic of Serbia performed the analysis of air pollution according to Manual Air Quality Monitoring System (AAQMS) [14].

\section{Results and discussion}

Annual levels of $\mathrm{SO}_{2}$ were higher than the allowed limit value, at all the tested sites for the period 2009-2015. On an annual level, concentrations of $\mathrm{SO}_{2}$, measured in different places in the zone of the city of Bor, were several times higher than the allowed values for the period 2011, 2012, 2014 and 2015. Daily $\mathrm{SO}_{2}$ concentrations measured at the suburban zone $\left(3734 \mu \mathrm{g} / \mathrm{m}^{3}\right)$ were even 187 times higher than the allowable values given by the World Health Organization (Figure 2) [4]. The highest concentration of $\mathrm{SO}_{2}$ in the air was at the measuring points of the Technical Faculty and Jugopetrol. These locations are placed in the direction of the east and west wind. The second most polluted location was the City Park. The city park is close to the copper smelter and under the influence of east winds. The results of research by Serbula and associates [4] indicate that due to the high concentration of $\mathrm{SO}_{2}$ the city of Bor could be marked as the most polluted region in this part of the Balkans.

Tasić, et al. [1] reported that, during 2004-2009, concentrations of suspended particles were in direct agreement with the high concentration of $\mathrm{SO}_{2}$ and inverse agreement with the wind speed. Pollution occurred in episodes. Namely, in different seasons and in a period of several hours during the day there was pollution with PM10 particles ( $\max$ values = $72.7-393.7 \mu \mathrm{g} / \mathrm{m}^{3}$ ) higher than the daily allowable limit $(50 \mu \mathrm{g} /$ $\mathrm{m}^{3}$ ). The share of $\mathrm{PM}_{10}$ particles in total suspended particles was generally more than $70 \%$ (Table 1 ).

The outcomes of research on the degree of air pollution from previous years (2004-2015; Table 1, Figure 2) in the region of the city of Bor, indicate that the concentration of all pollutants is considerably higher. But, the results of research by different authors differ for the same years and do not agree (Table 1). In addition, no continuous research has been done for all pollutants for several consecutive years.

Based on Article No21 of the Law on air protection in the Republic of Serbia, and according to the degree of pollution, 
starting from prescribed limit and tolerance values the following air quality categories have been identified:

1) First category - clean or lightly polluted air where the values for any pollutant do not exceed the limit;

2) Second category - moderately polluted air where the values of nitrogen dioxide exceeded, the limit but the tolerance and the values for other pollutants do not exceed the limit;

3) Third category - excessively polluted air where the values for one or more pollutants exceed the limit [14].

According to the data from AAQMS, the mean annual value of $\mathrm{SO}_{2}$ concentration above the limit value, $50 \mu \mathrm{g} / \mathrm{m}^{3}$, in 2019 year occurred at station Bor-Town Park where it was 54.8 $\mathrm{\mu g} /$ $\mathrm{m}^{3}$. Exceeding daily limit value $\left(125 \mathrm{\mu g} / \mathrm{m}^{3}\right)$ was registered at stations Bor-Town Park for 41 days, Bor-Brezonik for 11 days and at Bor-Institut for 8 days. Hourly limit value $\left(350 \mu \mathrm{g} / \mathrm{m}^{3}\right)$ was exceeded more than 24 times at the station Bor-Town Park (235 times), at the station Bor-Brezonik (101 times) and

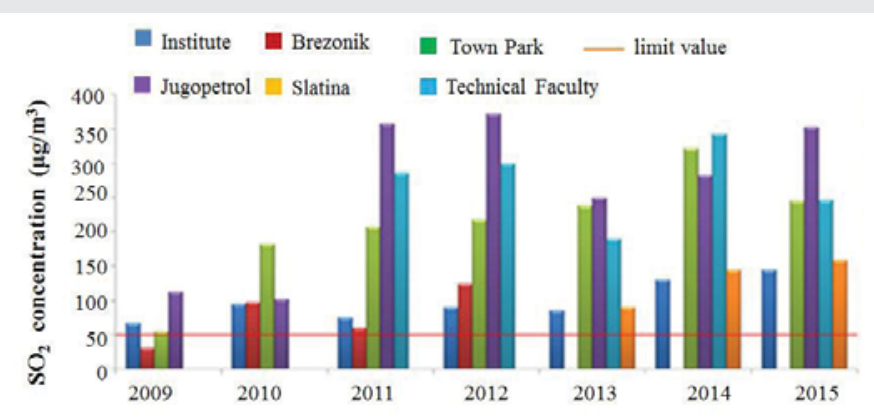

Figure 2: Concentration of SO2 during the 2009-2015 years in the zone of Bor Copper complex [4].

Table 1: Review of available literature for average annual contents of $\mathrm{SO}_{2}$ and $\mathrm{PM}$ particles in the town of Bor for the 2004-2009 periods (average value; $\mu \mathrm{g} / \mathrm{m}^{3}$ ).

\begin{tabular}{|c|c|c|c|c|c|c|}
\hline Location & Year & $\mathrm{SO}_{2}$ & $\mathrm{PM}_{10}$ & $\mathrm{PM}_{2.5}$ & $\mathrm{PM}_{1}$ & Reference \\
\hline \multirow{7}{*}{ Town Park } & 2004 & 86 & 41.1 & 22.7 & 9.6 & [1] \\
\hline & 2005 & 169 & - & - & - & [2] \\
\hline & \multirow{2}{*}{2006} & 227 & 32.7 & 14.0 & 5.7 & [1] \\
\hline & & 238 & - & - & - & \multirow{3}{*}{ [2] } \\
\hline & 2007 & 175 & - & - & - & \\
\hline & 2008 & 105 & 16 & - & - & \\
\hline & 2009 & 112 & 32.4 & 23.7 & - & [1] \\
\hline \multirow{5}{*}{ Institute } & 2005 & 66 & 7 & - & - & \multirow{2}{*}{ [2] } \\
\hline & \multirow{2}{*}{2006} & 86 & 8 & - & - & \\
\hline & & 62 & 38 & 16.0 & 6.7 & [1] \\
\hline & 2007 & 82 & 8 & - & - & \multirow{4}{*}{ [2] } \\
\hline & 2008 & 61 & 17 & - & - & \\
\hline \multirow{5}{*}{ Jugopetrol } & 2005 & 215 & - & - & - & \\
\hline & 2006 & 199 & - & - & - & \\
\hline & 2000 & 178 & 44.1 & 19.1 & 6.9 & [1] \\
\hline & 2007 & 189 & - & - & - & \multirow{5}{*}{ [2] } \\
\hline & 2008 & 170 & 11 & - & - & \\
\hline \multirow{5}{*}{ Brezonik } & 2005 & 58 & 7 & & & \\
\hline & 2006 & 104 & 5 & & & \\
\hline & 7002 & 91 & 5 & & & \\
\hline & 2007 & 44 & 42.5 & - & - & \multirow{2}{*}{ [1] } \\
\hline & 2008 & 68 & 45 & - & - & \\
\hline
\end{tabular}

at the station Bor-Institut (91 times). In the annual report on air pollution for year 2019, the Environmental Protection Agency of the Republic of Serbia did not show the results for PM particles for the city of Bor. But this agency estimated that the air quality in the region of the city of Bor was the third category (Figure 3) [14].

\section{Conclusion}

Today, air pollution in Serbia is a serious problem, which has a direct impact on human health. The results of the analysis of the air in Bor Copper complex region show that the concentration of $\mathrm{SO}_{2}$ and $\mathrm{PM}$ particles is above the recommended values at all measurement points. There is no data in the literature on research in the recent period, except for the report of the Ministry of environmental protection of the Republic of Serbia, which indicates a serious problem in this area. Furthermore, the results of scientific tests show significant differences in the results for the same research period. Large pollution intensity for a few hours, one or more times during the day, can lead to an exceedance of the daily average limit value. Meteorological parameters of the wind direction and speed are very important factors for the distribution of particles in the air. Due to the geographical position of Bor smelter, air pollution can also occur in the wider Balkan region (e.g. Bulgaria and Romania). In fact, the current ethical question is being posed to representatives of Bor Copper complex, government officials of Serbia and the scientific community in Serbia - how to solve the serious problem of environmental pollution, which has a great impact on human health?

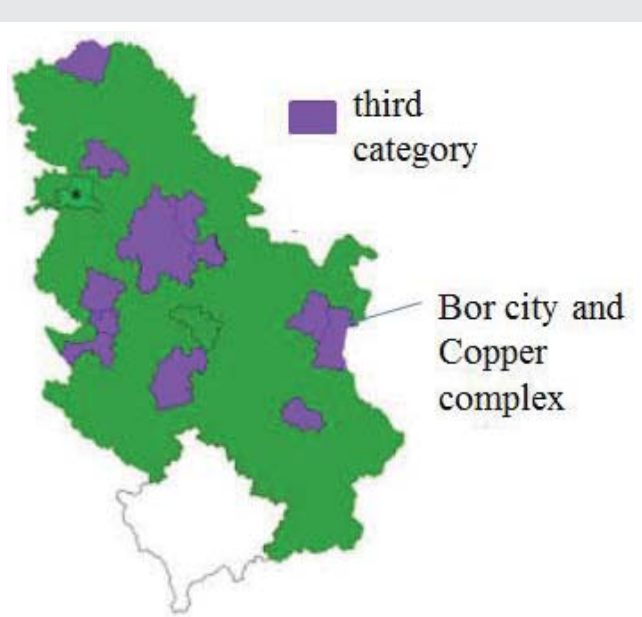

Figure 3: Categories of air quality for 2019 - assessment in accordance with the Law on Air Protection in Republic of Serbia (Environmental Protection Agency of the Republic of Serbia, 2020).

\section{References}

1. Tasić V, Milošević N, Kovačević R, Petrović N (2010) The analysis of air pollution caused by particle matter emission from the Copper Smelter complex Bor (Serbia). Chemical Industry and Chemical Engineering Quarterly 16: 219-228. Link: https://bit.ly/3tKsArU

2. Nikolić DJ, Milošević N, Mihajlović I, Živković Ž, Tasić V, et al. (2010) Multicriteria analysis of air pollution with $\mathrm{SO}_{2}$ and $\mathrm{PM}_{10}$ in urban area around 
the Copper Smelter in Bor, Serbia. Water, Air \& Soil Pollution 206: 369-383. Link: https://bit.ly/3dITRW3

3. Mrazovac Kurilić S, Božilović Z, Milošević R (2020) Contamination and health risk assessment of trace elements in $\mathrm{PM}_{10}$ from mining and smelting operations in the Bor Basin, Serbia. Toxicology and Industrial Health 36: 135 145. Link: https://bit.ly/3tKsoca

4. Serbula MS, Milosavljevic SJ, Radojevic AA, Kalinovic VJ, Kalinovic ST (2017) Extreme air pollution with contaminants originating from the mining-metallurgical processes. Sci Total Environ 586: 1066-1075. Link: https://bit.ly/2PdVxOf

5. Su S, Li B, Cui S, Tao S (2011) Sulfur dioxide emissions from combustion in China: from 1990 to 2007. Environmental Science \& Technology 45: 84038410. Link: https://bit.ly/3vqJDzR

6. World Health Organization (2019) Health impact of ambient air pollution in Serbia. WHO Regional Office for Europe, Copenhagen, Denmark. Link: https://bit.ly/3xi30kW

7. World Health Organization (2000) Air quality guidelines for Europe (2nd ed.). WHO Regional Publications, Regional Office for Europe, Copenhagen, Denmark. Link: https://bit.ly/3vgDt4S
8. Sánchez de la Campa AM, Sánchez-Rodas D, Gonzáles Castanedo Y, de la Rosa JD (2015) Geochemical anomalies of toxic elements and arsenic speciation in airborne particles from Cu mining and smelting activities: influence on air quality. J Hazard Mater 291:18-27. Link: https://bit.ly/32Icz9U

9. Koelemeijer RBA, Homan CD, Matthijesen J (2006) Comparison of special and temporal variations of aerosol optical thickness and particulate matter over Europe. Atmospheric Environment 40: 5304-5315. Link: https://bit.ly/32D6CLB

10. EU (1999) 1999/30/CE Council Directive relating to limit values for sulphur dioxide, nitrogen dioxide and oxide of nitrogen, particulate matter and lead in ambient air. The Council of the European Union. Link: https://bit.ly/3er4xYp

11. European Commission (2019) Air quality standards. Link: https://bit.ly/3sSi8NX.

12. 2008/50/EC European Parliament (2008). Link: https://bit.ly/3awkhly

13. Commission Regulation (EC) No 2341/1999. (1999).

14. Environmental Protection Agency of the Republic of Serbia (2020) Annual report on the state of air quality in the Republic of Serbia 2019. Ministry of environmental protection of the Republic of Serbia. Link: https://bit.ly/3eiExyk
Discover a bigger Impact and Visibility of your article publication with Peertechz Publications

\section{Highlights}

* Signatory publisher of ORCID

* Signatory Publisher of DORA (San Francisco Declaration on Research Assessment)

* Articles archived in worlds' renowned service providers such as Portico, CNKI, AGRIS, TDNet, Base (Bielefeld University Library), CrossRef, Scilit, J-Gate etc.

* Journals indexed in ICMJE, SHERPA/ROMEO, Google Scholar etc.

* OAI-PMH (Open Archives Initiative Protocol for Metadata Harvesting)

* Dedicated Editorial Board for every journal

* Accurate and rapid peer-review process

* Increased citations of published articles through promotions

* Reduced timeline for article publication

Submit your articles and experience a new surge in publication services

(https://www.peertechz.com/submission).

Peertechz journals wishes everlasting success in your every endeavours.

Copyright: @ 2021 Stanojevic AB. This is an open-access article distributed under the terms of the Creative Commons Attribution License, which permits unrestricted use distribution, and reproduction in any medium, provided the original author and source are credited. 